\title{
As Representações Sociais da Dança: um Mergulho no Universo dos Estudantes de Bacharelado em Educação Física
}

\section{Dance Social Representations: a Dive into the Universe of Physical Education Bachelor Students}

\author{
Felipe da Silva Triani ${ }^{\mathrm{a}}$; Glhevysson dos Santos Barros ${ }^{\mathrm{b}}$ \\ ${ }^{a}$ Faculdade Gama e Souza. RJ, Brasil. \\ ${ }^{\mathrm{b} S e c r e t a r i a ~ M u n i c i p a l ~ d e ~ E d u c a c ̧ a ̃ o ~ d o ~ R i o ~ d e ~ J a n e i r o . ~ R J, ~ B r a s i l ~}$ \\ *E-mail: felipetriani@gmail.com
}

\begin{abstract}
Resumo
A dança é a arte de movimentar expressivamente o corpo seguindo movimentos ritmados, em geral ao som de música. Dessa forma, o significado da dança vai além da expressão artística, podendo ser vista como um meio para adquirir conhecimentos ou como opção de lazer. No campo de atuação do bacharelado, as investigações acadêmicas ainda são tímidas, urgindo de produções científicas que possam alimentar o campo científico sobre o tema. Dessa forma, o objetivo do estudo foi identificar e analisar as representações sociais que um grupo de bacharelandos do curso em Educação Física compartilha sobre a dança. A metodologia da pesquisa envolve uma abordagem qualitativa, tendo o estudo de campo como procedimento técnico. A amostra foi constituída por 200 indivíduos, sendo 85 homens e 115 mulheres com médias de idade entre 17 a 45 anos. A coleta de dados ocorreu através de questionário com associação livre de palavras, cujo termo indutor foi "dança". A análise foi feita por meio dos conteúdos das respostas. O resultado principal do estudo apontou que a maioria dos estudantes emprega sentido de dança como uma atividade técnica e a associam com saúde mental e bem-estar.
\end{abstract}

Palavras-chave: Representação Social. Educação Física. Dança.

\begin{abstract}
Dance is the art of expressively moving the body following rhythmic movements, usually to the sound of music. Thus, the meaning of dance goes beyond artistic expression, and can be seen as a means to acquire knowledge or as a leisure option. In the field of performance of the bachelor's degree, academic investigations are still timid, urging scientific productions that can feed the scientific field on the theme. Thus, the objective of the study was to identify and analyze the social representations that a group of Physical Education course bachelors shares about dance. The research methodology is a qualitative approach, with the field study as a technical procedure. The sample consisted of 200 individuals, 85 men and 115 women with a mean age between 17 and 45 years. Data collection was carried out through a questionnaire with free association of words, whose inducing term was, "dance". The analysis was done through the responses content. The main result of the study pointed out that most students use dance as a technical activity and associate it with mental health and well-being.
\end{abstract}

Keywords: Social Representation. PE. Dance.

\section{Introdução}

Segundo Hass e Garcia (2006), a dança é a arte de se movimentar expressivamente o corpo seguindo movimentos ritmados, em geral ao som de música. O povo primitivo iniciou a arte de dançar e a praticava em diferentes ocasiões: no período de colheita, no ritual aos deuses, na época das caçadas, nos casamento em momentos de alegria ou de tristezas ou ainda em homenagem à natureza. É considerada a mais completa das artes, pois envolve elementos artísticos, como: a música, o teatro, a pintura e a escultura, sendo capaz de exprimir das mais simples às mais fortes emoções.

O significado da dança vai além da expressão artística, podendo ser vista como um meio para adquirir conhecimentos ou como opção de lazer. Através da dança uma pessoa pode expressar o seu estado de espírito. Há a possibilidade, ainda, de estar acompanhada por instrumentos de percussão, melódicos ou ainda pela leitura de diferentes textos (HASS; GARCIA, 2006).

Segundo Guimaraes (2003), Garcia e Glitz (2009), a dança é a arte do movimento humano, essa é plástico-rítmica, abstrata e expressiva, umas das artes mais antigas conhecidas, aparecendo desde os primórdios das civilizações como uma manifestação natural, muitas vezes como forma de ritual, a dança promove desenvolvimento integral do ser humano (SILVA; MARTINS; MENDES, 2012).

Ainda que exista o Curso Superior para a formação de profissionais de dança, há possibilidade de intervenção nessa área pelo professor de Educação Física, ainda que com abordagem específica. De acordo com as diretrizes do Conselho Federal de Educação Física (2010), no que se refere ao campo de atuação desse profissional, a dança se caracteriza como objeto de conhecimento possível de ser tematizado na Educação Física, seja com objetivo educacional no campo da educação ou de promoção de saúde e condicionamento físico no ambiente não formal.

Ao adotar a Teoria das Representações Sociais (MOSCOVICI, 2012) como referencial teórico e metodológico para o desenvolvimento do estudo, se faz necessário considerar 
que de acordo com a referida teoria, as representações sociais sobre o objeto da representação são possíveis indícios que possibilitam compreender a ação do grupo sobre o objeto. Portanto, parte-se do pressuposto de que as representações sociais que o grupo de estudantes em formação compartilha sobre a dança pode servir como caminho para compreender sua relação psicossocial no e sobre essa.

Estudos anteriores (BRASILEIRO, 2008; SILVA; COSTA, 2017) apontam que a dança é um componente curricular obrigatório que está presente nos cursos de licenciatura e bacharelado em Educação Física no Brasil. No entanto, essas investigações desvelam que a dança é tematizada em uma ou duas disciplinas da grande curricular. Desse modo, considerando essas evidências, bem como o referencial teórico utilizado no presente texto, sendo possível sinalizar que a atuação com a dança vai depender das representações sociais que o grupo em formação compartilha sobre essa, algo que depende dos desfechos vivenciados junto à dança e no campo de atuação do bacharelado as investigações acadêmicas ainda são tímidas, urgindo de produções científicas que possam alimentar o campo científico sobre o tema. Diante desses entendimentos, o presente manuscrito objetivou identificar e analisar as representações sociais que um grupo de bacharelandos em Educação Física compartilha sobre a dança.

\section{Material e Métodos}

Trata-se de uma pesquisa com abordagem qualitativa, tendo o estudo de campo como procedimento técnico que, conforme Severino (2007), é a averiguação que trata o objeto em seu ambiente próprio e a coleta de dados é realizada nas condições naturais em que os fenômenos acontecem.

Por conveniência, participaram do estudo 200 alunos, sendo 115 do sexo feminino e 85 do masculino, com média de idade entre 17 e 45 anos, do curso de bacharelado em Educação Física, do primeiro ao oitavo período, dos turnos matutino e vespertino de uma Instituição privada localizada na Zona Oeste da cidade do Rio de Janeiro.

A coleta de dados ocorreu no segundo semestre do ano de 2018 por meio do Teste de Associação Livre de Palavras (TALP), ou também denominado de Evocação Livre de Palavras (ELP) ou Associação Livre (AL) (CARMO; LEITE; MAGALHÃES JÚNIOR, 2017), no qual os alunos escreveram as cinco primeiras palavras que lhes vieram à mente a partir da expressão indutora "Dança" e, logo após, as classificaram de acordo com o grau de importância, atribuindo o número um para a mais importante, até cinco para a menos importante (TRIANI; MAGALHÃES JÚNIOR; NOVIKOFF, 2017). Cabe ressaltar que o TALP é um dos instrumentos mais utilizados em estudos e pesquisas que adotam como referencial teórico e metodológico a Teoria das Representações Sociais de abordagem estrutural (TRIANI; MAGALHÃES JÚNIOR, 2017). Cabe destacar que os questionários foram entregues aos alunos nas salas de aulas, no intervalo entre uma aula e outra. Cada discente demorava cerca de 3 minutos para responder o questionário. Não houve realização de grupo controle.

A análise das palavras foi realizada identificando os elementos centrais e periféricos das representações como sugerido por Sá (1996). Utilizando as fórmulas para determinação da Ordem Média de Evocação $(\mathrm{OME})^{1}$, média da $\mathrm{OME}^{2}$ e frequência média das evocações ${ }^{3}$ (MAGALHÃES JÚNIOR; TOMANIK 2012; GALVÃO; MAGALHÃES JÚNIOR 2016), foram identificados os elementos centrais e periféricos. A seguir, as palavras foram organizadas em um quadro com quatro quadrantes: no primeiro quadrante se encontram os elementos pertencentes ao núcleo central; quarto quadrante se localizam os elementos periféricos e; nos segundo e terceiro quadrantes os elementos intermediários.

Todos os alunos participaram como voluntários e assinaram o Termo de Consentimento Livre e Esclarecido (TCLE), sendo respeitados os critérios éticos e legais em pesquisas envolvendo seres humanos de acordo com a Resolução 466 de 2012. Cabe ressaltar que a pesquisa foi aprovada pelo Comitê de Ética em Pesquisa: CAAE de 41355114.3.0000.5283.

\section{Resultados e Discussão}

Analisando o Quadro 1, é possível perceber que no primeiro quadrante a palavra "técnica" emergiu com 193 de frequência e 3,15 de OME. Em seguida, tem-se "saúde mental" com frequência de 151 e 3,49 de OME. Esses termos, possivelmente, são os elementos centrais que compõem o núcleo central das representações sociais sobre a dança.

Quadro 1 - Elementos das representações sociais dos estudantes do curso de bacharelado em Educação Física sobre a dança

\begin{tabular}{|c|c|c|c|c|c|}
\hline \multicolumn{3}{|c|}{$\begin{array}{c}\text { Elementos Centrais - } 1^{\circ} \\
\text { Quadrante }\end{array}$} & \multicolumn{3}{|c|}{$\begin{array}{c}\text { Elementos Intermediários - } \\
2^{\circ} \text { Quadrante }\end{array}$} \\
\hline \multicolumn{3}{|c|}{$\begin{array}{l}\text { Alta f e baixa Ordem Média } \\
\text { de Evocações } \\
\mathrm{F}>107 \text { e OME }<4,04\end{array}$} & \multicolumn{3}{|c|}{$\begin{array}{l}\text { Alta F e alta Ordem Média de } \\
\text { Evocações } \\
F>107 \text { e OME }>4,04\end{array}$} \\
\hline Palavra & Freq. & OME & Palavra & Freq. & OME \\
\hline $\begin{array}{l}\text { Saúde Mental } \\
\text { Técnica }\end{array}$ & $\begin{array}{l}151 \\
193\end{array}$ & $\begin{array}{l}3,49 \\
3,15\end{array}$ & Sentimento & 295 & 4,64 \\
\hline \multicolumn{3}{|c|}{$\begin{array}{l}\text { Elementos Intermediários - } \\
3^{\circ} \text { quadrante }\end{array}$} & \multicolumn{3}{|c|}{$\begin{array}{l}\text { Elementos Periféricos }-4^{0} \\
\text { quadrante }\end{array}$} \\
\hline \multicolumn{3}{|c|}{$\begin{array}{l}\text { Baixa F e baixa Ordem Média } \\
\text { de Evocações } \\
\mathrm{F}<107 \text { e OME }<4,04\end{array}$} & \multicolumn{3}{|c|}{$\begin{array}{l}\text { Baixa } F \text { e alta Ordem Média de } \\
\text { Evocações } \\
F<107 \text { e OME }>4,04\end{array}$} \\
\hline Palavra & Freq. & OME & Palavra & Freq. & OME \\
\hline $\begin{array}{l}\text { Movimento } \\
\text { Disciplina } \\
\text { Cultura } \\
\text { Divertimento } \\
\text { Atividade } \\
\text { Física }\end{array}$ & $\begin{array}{l}82 \\
26 \\
5 \\
46 \\
64\end{array}$ & $\begin{array}{l}3,25 \\
3,26 \\
3 \\
2,86 \\
3,03\end{array}$ & & & \\
\hline
\end{tabular}

Fonte: dados da pesquisa. 
No segundo quadrante, dimensão que faz referência aos elementos intermediários das representações sociais do grupo, "sentimento" surge com frequência de 295 e 4,64 de OME.

No terceiro quadrante se percebe que as palavras "movimento", "disciplina", "cultura", "divertimento" e "atividade física" compõem também o quadrante de elementos considerados intermediários das representações sociais, porém mais próximos do sistema periférico. A palavra "movimento" foi a de maior frequência, com 82 e 3,25 de OME. A segunda palavra com maior frequência nesse quadrante foi atividade física com 64 e 3,03 de OME, seguida de "divertimento" com 46 de frequência e 2,86 de OME, "disciplina" com 26 de frequência e 3,26 de OME e "cultura" com 5 de frequência e 3 de OME.

Nesse contexto, foi possível identificar que para o grupo de estudantes em formação, as representações sociais sobre a dança estão associadas à técnica e à saúde mental.

$\mathrm{O}$ texto em tela buscou identificar e analisar as representações sociais que um grupo de bacharelandos em Educação Física compartilha sobre a dança. Sendo assim, após a coleta dos dados foi observado que a técnica se mostrou como um grupo semântico que muito expressivo com alta frequência e baixa ordem média de evocação, desvelando ser majoritariamente o elemento mais importante associado à dança nas representações sociais dos estudantes.

Ao analisar os elementos presentes no núcleo central da estrutura das representações sociais dos bacharelandos, é possível que "técnica" e "saúde mental" sejam representações sociais do senso comum, mas que estão presentes no universo reificado. Esse fenômeno é possível, considerando que as observações postas por Silva e Costa (2017) indicam que durante toda a graduação, somente uma ou duas disciplinas do curso tematizam a dança. Desse modo, é possível que esse diminuto contato com a prática não seja o suficiente para que o estudante perceba que a atuação na e sobre a dança não se restringe ao fato de possuir técnica ao ponto de "dançar bem" ou "ser dançarino".

Estudos anteriores assinalam que tanto no ambiente formal (FINCK; CAPRI, 2011) como no ambiente informal (BRASILEIRO, 2008), o ensino da dança tem se restringido ao processo de ensaios coreográficos que são postos em exposição, posteriormente, por meio de apresentações em eventos comemorativos, não sendo uma prática corporal tematizada ou habitual. Nesse contexto, é importante destacar que essas práticas parecem estar muito mais associadas ao reforço das representações sociais de que as aulas de dança servem como espaços de ensaio para futuras apresentações, do que o ensino de competências e habilidades que servirão como estratégias de intervenção profissional.

Essas representações sociais sobre a dança podem ser indícios de que a formação de professores pode não estar contribuindo para a construção de habilidades e de competências que capacitarão o futuro profissional para atuar no campo da dança. Essa asserção é oportuna, na medida em que está descrita nas Diretrizes Curriculares Nacionais dos Cursos de Graduação em Educação Física (BRASIL, 2018), que a formação do Bacharel em Educação Física deve qualificar o estudante para a intervenção acadêmica e profissional em dança, visando ampliação e enriquecimento cultural para a promoção de um estilo de vida fisicamente ativo e saudável.

No estudo realizado por Assumpção, Macara e Januário (2016), os autores identificaram as representações de professoras de dança sobre práticas inclusivas de um programa educacional de artes da Secretaria Municipal de Educação do Rio de Janeiro. No entanto, cabe destacar que este projeto pode ter atuação tanto de professores de dança como de profissionais de Educação Física com formação em bacharelado. O objetivo do estudo foi identificar quais os tipos de estratégias de ensino e recursos pedagógicos são implementados para atenuar a exclusão dos adolescentes com deficiências das aulas.

Participaram da amostra 15 professores de dança dos núcleos de artes da prefeitura do Rio de Janeiro. Para a coleta dos dados, foram realizadas entrevistas semiestruturadas. Com os resultados apresentados, verifica-se que as estratégias de ensino e recursos pedagógicos visam garantir aprendizagem em dança e o desenvolvimento de competências emocionais e sociais dos alunos com ou sem deficiência. Neste caso, a dança nesse estudo tem um fator de inclusão, diferente da pesquisa apresentada na Quadro 1, que a técnica ganha destaque.

Já em outro estudo realizado por Grego et al. (1999), os autores apontaram que a dança pode causar diversas lesões até mesmo em profissionais da área. Logo, a orientação e as medidas preventivas são de suma importância para que os praticantes iniciantes da dança não se lesionem. Para tanto, realizou-se estudo com 122 bailarinas na faixa etária de 8 a 30, alocadas nas academias de dança da cidade de Bauru, área de atuação tanto dos profissionais de dança como dos professores de Educação Física com habilitação em bacharelado. Os resultados apontaram que $53,27 \%$ das respondentes com frequências entre 1 e 6 lesões agudas, que aumentam com idade, concentram-se no plano tegumentar $(79,46 \%)$ e estão associadas às variáveis como a idade em que começou a dançar e com o uso da sapatilha de ponta; $97,48 \%$ são agravos de membros inferiores, com predominância de calos $(47,03 \%)$ e bolhas $(28,56 \%)$ nos pés.

Segundo Grego et al. (1999), o bale clássico foi estilo responsável pela maior parte das lesões, as mais experientes e as estudantes foram mais afetadas pelo uso da sapatilha de ponta, que implicou risco elevado para ocorrências dos agravos observados nos pés. Apesar da técnica apurada dessas bailarinas, alguns fatores levaram a essas lesões como apresentado. Sabe-se que a técnica é importante, mas outros fatores que fazem parte da dança também são de suma importância e as lesões, muitas vezes, não estão associadas à falta de técnica e sim a outros fatores como mostrou o estudo acima. 
Em estudos que pesquisaram sobre os benefícios da dança, no contexto da saúde mental, Silva, Valente e Borragine (2012) destacam que a dança como qualquer atividade aeróbia libera endorfina, causando uma sensação de bem-estar, além de melhorar o equilíbrio e aumentar as capacidades das regiões do cérebro que diminuem com o tempo. No plano emocional, a dança atua na transformação das emoções do indivíduo, incutindo, em ser mais leveza, mais suavidade e beleza, ao mesmo tempo em que trabalha a confiança e a segurança. A dança trabalha o desbloqueio de sentimentos reprimidos, ajudando o indivíduo a liberar verbalmente seus temores e, no plano mental, o raciocínio se torna mais ágil, estimula a memória e favorece maior concentração da atenção. Como analisado se nota que a dança favorece benefícios da saúde mental a quem pratica. Em comparação aos estudos se pode perceber que a dança pode ajudar no combate a depressão, ansiedade, estresse e outras coisas mais, além de melhorar o autoconceito e autoestima (MAIA; SILVA, 2012).

Segundo Maia e Silva (2012, p. 28), a dança é "importante instrumento de expressão e comunicação de emoções e sentimentos", além de ajudar "no desenvolvimento das grandes funções mentais como atenção, memória, raciocínio e imaginação". Portanto, a dança ganha destaque na contribuição que proporciona relações interpessoais e na saúde mental com a redução dos níveis de estresse, de ansiedade e no combate ao sedentarismo (MARCELINO; KNIJNIK, 2006; MAIA; SILVA, 2012).

Com relação à prática da dança, Leite (2000) apresenta alguns benefícios como: aumento da sensação de bem-estar, redução da ansiedade, da depressão, ou seja, benefício que a dança promove, em especial, para a saúde mental do indivíduo que pratica. É importante mencionar conforme relata a figura 1, a questão das representações com relação à prática da dança, a saúde mental ganha destaque já que melhora em diversos aspectos como demonstrado acima.

Já Castro (2006) reforça sobre a importância da dança, que é uma intervenção prática que estrutura a criação de novas alternativas para quem a pratica, rompendo com a cultura do isolamento, além de promover a socialização e melhora na saúde mental de quem pratica a dança.

Já o grupo semântico "sentimento", presente no elemento intermediário, como apresentado no segundo quadrante da Figura 1, está muito associado à dança, pois são reações que o corpo é capaz de expressar diante de emoções e até mesmo de prazer ao praticar (SILVA, 2009).

Já no terceiro quadrante, embora os elementos "atividade física", "movimento", "disciplina", "cultura" e "divertimento" sejam grupos semânticos separados, ambos estão intimamente relacionados à dança, na medida em que o praticante regular obtém resultados positivos sobre a saúde e a qualidade de vida (SILVA; VALENTE; BORRAGINE, 2012).

Ainda que o grupo amostral tenha apresentado indícios de representações sociais associados à da saúde mental e à técnica em seu núcleo central, sendo importante destacar que muitos estudantes têm o primeiro contato com a dança no curso de graduação em Educação Física, conforme identificou Lucca et al. (2019) ao investigar 127 estudantes desse curso, dos quais $59,8 \%$ tiveram o primeiro contato com a prática na graduação.

Como as representações sociais são conhecimentos socialmente compartilhados entre os indivíduos de um grupo (JODELET, 2001) e são adquiridas com o processo de comunicação (MOSCOVICI, 2012), na medida em que há carência de conhecimentos presentes no universo reificado ${ }^{4}$, o que é compartilhado são os conhecimentos do universo consensual $^{5}$, fazendo com que o grupo apresente somente saberes relativos ao senso comum desprovidos de ciência.

Se por um lado, o contato com a dança na graduação permite que o estudante compartilhe seu conhecimento prévio, por vezes equivocado, sobre essa prática corporal, por outro também desperta o interesse como efeito da experimentação. Lucca et al. (2019), ao realizarem uma pesquisa com estudantes de um curso de Educação Física, perceberam que $48 \%$ dos integrantes do grupo que participou do estudo afirmaram ter passado a gostar mais da dança em função da vivência durante o curso.

Marani e Sborquia (2019) ressaltam a necessidade de tematizar a dança na formação do profissional de Educação Física, pois de acordo com sua investigação se torna necessário compreender a dança na formação desse professor, a fim de que o trato pedagógico com a prática possibilite transformações paradigmáticas sobre a dança, fazendo emergir as competências de ludicidade, de espontaneidade e de criação, basilares para a formação do profissional.

\section{Conclusão}

De acordo com o que foi apresentado, no estudo proposto sobre as representações sociais da dança, por um grupo de estudantes de bacharelado em Educação Física de uma Instituição privada localizada na Zona Oeste da cidade do Rio de Janeiro, percebe-se que a dança é uma prática corporal ainda pouco conhecida pelos professores, pois foi observado que técnica e saúde mental se desvelaram como um grupo semântico com alta frequência, apresentando ser predominantemente os elementos mais importantes associados à dança nas representações sociais do grupo.

Compreender as representações sociais que esses alunos apresentam é essencial para entender seus comportamentos

4 Universo reificado - trata-se do ambiente em que reside a comunidade científica, esfera em que são compartilhados os conhecimentos científicos concernentes a um determinado objeto de estudo.

5 Universo consensual - faz referência ao ambiente em que o saber comum é compartilhado, isto é, o senso comum, conhecimento socialmente aceito e compartilhado, mas sem fundamentação científica. 
sobre o tema estudado, bem como propor uma análise para possíveis modificações sobre as representações sociais e, em consequência disso, o modo de como agir de forma social.

Portanto, esses indícios de representações sociais sobre a dança caminham em direção à necessidade de uma formação mais abrangente sobre o grupo que foi investigado, já que os discentes ainda estão em formação e possuem, ainda, conhecimento limitado sobre a importância dessa prática nos espaços como praças, projetos e clubes. Dessa maneira, é possível que na graduação haja, por parte dos professores, ações que possibilitem a otimização dos conhecimentos sobre a dança, garantindo atividades de formação como palestras e cursos que abordem sobre a importância dessa prática com intuito de transformar as representações sociais em conhecimentos científicos, presentes no universo reificado. Cabe ressaltar que é preciso realizar mais pesquisas nesse campo, em outras regiões, com o objetivo de saber se essas representações sociais sobre a dança se repetem, considerando sua importância na área.

\section{Referências}

ASSUMPÇÃO, V.; MACARA, A.; JANUÁRIO, C. Práticas inclusivas na dança: estratégias de ensino das professoras de dança dos núcleos de arte. J. Res. Spec. Educ. Needs, v.16, p 880883, 2016.

BRASIL. Ministério da Educação. Conselho Nacional de Educação. Resolução CNE/CES n ${ }^{\circ}$ 6, de 18 de dezembro de 2018. Diretrizes Curriculares Nacionais dos Cursos de Graduação em Educação Física e dá outras providências. Diário Oficial da União, Brasília, no 243, seção 1, p. 48, 2018.

BRASILEIRO, L.T. O ensino da dança na Educação Física: formação e intervenção pedagógica em discussão. Motriz, v.14, n.4, p.519-528, 2008.

CARMO, T.; LEITE, J.C.; MAGALHÃES JÚNIOR, C. A. O. Aspectos Metodológicos em Representações Sociais: um olhar para as pesquisas no contexto educacional. In: TRIANI, F.S.; MAGALHÃES JÚNIOR, C.A.O.; NOVIKOFF, C. Representações sociais e educação: contextos e perspectivas. Rio de Janeiro: Autografia, 2017. p.7-112.

CASTRO, E. Dança, corporeidade e saúde mental: experimentações em terapia ocupacional. In: ARCURI, I. (Org.), Arteterapia de corpo e alma. São Paulo: Casa do Psicólogo, 2006.

CONSELHO FEDERAL DE EDUCAÇÃO FÍSICA. Resolução 206/2010, 07 de novembro de 2010. Dispõe sobre o Estatuto do Conselho Federal de Educação Física. Diário Oficial, BrasíliaDF, n. 237, Seção 1, p. 137-143, 2010.

FINCK, S.C.M.; CAPRI, F.S. As representações sociais da dança em aulas de educação física nos anos iniciais do Ensino Fundamental. Práxis Educ., v.6, n.2, p.249-263, 2011.

GALVÃO, C. B.; MAGALHÃES JÚNIOR, C. A. O. A relação entre as Representações Sociais de professores sobre Educação Ambiental e os projetos relacionados à Conferência Nacional Infanto juvenil pelo Meio Ambiente. Rev. Eletr. Mestr. Educ. Amb., v.33, n.2, p.124-141, 2016.

GARCIA A.; HAAS A.N. Ritmo e dança. Canoas: Ulbra, 2006.
GARCIA, J.L.; GLITZ, N.B. A influência da dança na qualidade de vida dos idosos. Buenos Aires, n.139, p. 1-4, 2009.

GREGO, L.G. et al. Lesões na dança: estudo transversal híbrido em academias da cidade de Bauru-SP. Rev. Bras. Med. Esporte, v.5, n.2, p.47-54, 1999.

JODELET, D. Representações sociais: um domínio em expansão. In: JODELET, D. (Org.). As representações sociais. Rio de Janeiro: UERJ, 2001. p.17-44.

LEITE, P.F. Fisiologia do exercício: ergometria e condicionamento físico. Cardiologia Desportiva. São Paulo: Robe, 2000.

LUCCA, I. L. et al. A contribuição das vivências em dança na formação dos docentes em Educação Física. Pensar a Prática, v. 22, p. 1-11, 2019

MAGALHÃES JÚNIOR, C.A.O.; TOMANIK, E. A. Representações sociais e direcionamento para a educação ambiental na Reserva Biológica das Perobas, Paraná. Investig. Ensin. Ciênc., v.17, n.1, p.227-248, 2012.

MAIA, L.B.; SILVA, R.M. A dança como estratégia de promoção da saúde para adolescentes. Cad. Cult. Ciênc., v.11, n.1, p. 25-37, 2012.

MARANI, V. H.; SBORQUIA, S. P. A dança na formação e desenvolvimento profissional em Educação Física: dimensões ético-estéticas em foco. Cad. Educ. Fís. Esporte, v.17, n.1, p.165271, 2019.

MARCELINO, E.P., KNIJNIK, J.D. A escola vai ao baile? Possíveis relações entre dança e Educação Física na escola. Rev. Mackenzie Educ. Fís. Esporte, v.5, n.1, p.65-72, 2006.

MOSCOVICI, S. Psicologia Social: sua imagem, seu público. São Paulo: Vozes, 2012.

SÁ, C.P. Representações sociais: teoria e pesquisa do núcleo central. Temas Psicol., v.3, n.1, p.19-33, 1996.

SEVERINO A.J. Metodologia do trabalho cientifico. São Paulo: Cortez, 2007.

SILVA, S.S. A dança: sentido e significados. EFDeportes.com, Rev. Dig., n. 139, p.1-4, 2009.

SILVA, M.G.B.; VALENTE, T.M.; BORRAGINE, S.O.F.A dança como prática regular de atividade física e sua contribuição para melhor qualidade de vida. EFDeportes.com, Rev. Digital, n. 166, p. 1-4, 2012.

SILVA, M.T.; COSTA, M.G.B. A disciplina de dança no curso de Educação Física de uma universidade particular do Sul do país. SEMINÁRIO INTERNACIONAL DE REPRESENTAÇÕES SOCIAIS, SUBJETIVIDADE E EDUCAÇÃO, p. 1124-1136, 2017.

SILVA, F.J.S.; MARTINS, L.; MENDES, C.R.S. Benefícios da dança na terceira idade. SEMINÁRIO DE PESQUISAS E TCC DA FUG. Faculdade de Umuarama, 2012.

TRIANI, F. S.; MAGALHÃES JÚNIOR, C.A.O.; NOVIKOFF, C.. As representações sociais de estudantes de Educação Física sobre a formação de professores. Movimento, v. 23, n.2, p.575$586,2017$.

TRIANI, F. S.; MAGALHÃES JÚNIOR, C. A. O. O estado do conhecimento sobre a produção científica brasileira face à teoria das representações sociais. In: YAEGASHI, S.F.R.; OLIVEIRA JÚNIOR, I. B.; SANTOS, A. R. (Org.). Psicologia e Educação: interfaces com as representações sociais. Curitiba: CRV, 2017. p. $61-70$. 